\title{
NASA ponders 'carbon copy' of crashed mission
}

Since the Orbiting Carbon Observatory (OCO) crashed into the ocean minutes after its 24 February launch, researchers at NASA and elsewhere have been working on how else they might get the data on atmospheric carbon dioxide levels that the mission was meant to collect.

Within a week of losing the satellite, NASA, which spent US\$278 million and seven years developing OCO, put together a committee of two dozen climate scientists to weigh up various options. Should they rebuild OCO with existing designs and launch it as quickly as possible? Start a new design that would take longer to develop? Or fund ground and sub-orbital carbon measurements, while working with "In all our opinions, the need for these data is just as high, if not higher, now as when the observatory was first planned."

with lasers will eventually offer a way to get round-the-clock data and thus see important effects such as those of nocturnal respiration by soil organisms.

But laser-based systems are technologically challenging. In a recent competition to design atmospheric-science satellites the European Space Agency eliminated a laser-based carbondioxide-monitoring mission, A-Scope, citing insufficient readiness. The technology for a similar NASA mission called ASCENDS (Active Sensing of $\mathrm{CO}_{2}$ Emissions over Nights, Days and Seasons) is still in development.

Crisp, who chaired the postOCO working group, says that something like ASCENDS wouldn't launch until at least existing greenhouse-gas monitoring satellites such as Europe's Envisat and Japan's Greenhouse gases Observing Satellite (GOSAT, also known as IBUKI).

The case against reincarnating $\mathrm{OCO}$ is that the spectroscopy it used to measure carbon levels needed reflected sunlight to work, preventing it from making measurements at dawn, dusk and night. Many scientists, including OCO's principal investigator David Crisp, of the Jet Propulsion Laboratory in Pasadena, California, think that probing the atmosphere
2015. Other options - putting OCO-type instruments on weather satellites or on the International Space Station (ISS) - would also take a long time, and in the case of the ISS would miss the polar regions.

So - as expected - the bottom line of the report by Crisp's committee, submitted to NASA on 2 April, was that the agency should build an OCO "Carbon Copy" with the same design and instruments and launch it as soon as possible. Getting the data quickly is "critical to support national policy initiatives", says

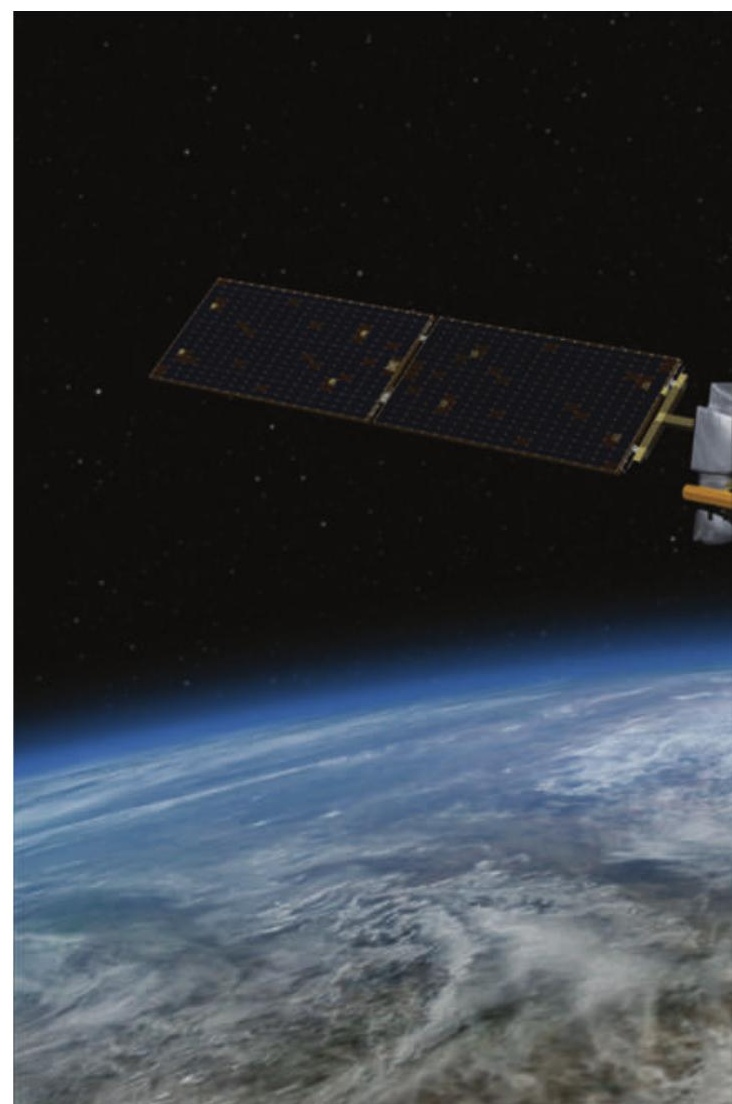

Crisp. The repeated mission would cost more $\vec{D}$ or less what OCO cost, and could be ready for launch in the autumn of 2011.

Michael Freilich, head of NASA's Earthscience division, has sent the white paper out for review and says he will make a decision "possibly in May". But even if he plumps for a rebuild, paying for it might be difficult. As

\section{Collision debris increases risk to Earth-observing satellites}

The collision of two communications satellites on 10 February has significantly increased the risk to Europe's Earth-observing programme. The European Space Agency's ERS-2 and Envisat missions are $30 \%$ more likely to face a catastrophic impact from space debris in the wake of the collision, according to Heiner Klinkrad, head of ESA's Space Debris Office in Darmstadt, Germany. The absolute risk remains small, but there were seven 'near misses' last year in which objects passed within 200 metres of the satellites. The satellites provide a range of environmental data, including in the case of Envisat some measurements of carbondioxide levels similar to, although less precise than, those that were expected from NASA's lost Orbiting Carbon Observatory (see "NASA ponders 'carbon copy' of crashed mission", above).

The increased hazard is the outcome of a collision between a spacecraft in the Iridium satellite constellation and a defunct Russian military satellite (see Nature 457, 940; 2009).

At present, the debris cloud from the collision contains roughly 800 items of 10 centimetres or larger.
Models show that number could rise to more than a thousand by the end of the month, says Richard Crowther, head of the United Kingdom's delegation to the United Nations Committee on the Peaceful Uses of Outer Space.

The debris field is smaller and more concentrated than many had originally feared, according to Brian Weeden, a technical consultant with the Secure World Foundation, based in Superior, Colorado.

That is probably because the two satellites dealt each other only a glancing blow. "It wasn't a dead-on collision," he says.

The concentrated debris field means that only satellites at fairly similar altitudes face a significantly enhanced risk. That could include some US and Canadian Earth-observing satellites. But spacecraft farther away, such as the Hubble Space Telescope and, when it services Hubble, the space shuttle Atlantis, seem relatively safe. US Space Command is tracking the larger pieces of debris, and ESA is making its own radar measurements, with the aim of arranging evasive action, if necessary, to avoid another accident.

Geoff Brumfiel 